\title{
AN INTERVENTIONAL STUDY ON KNOWLEDGE OF BREASTFEEDING AMONG MEDICAL STUDENTS IN A MEDICAL COLLEGE OF CENTRAL KERALA
}

\author{
Ann Mary Thomas ${ }^{1}$, Reshma², Avani Dinesh ${ }^{3}$, Harsha Chollankil Hariharan ${ }^{4}$, Swati Patki ${ }^{5}$, Gopalakrishnan Padmanabhan ${ }^{6}$, \\ Krishnan Nair ${ }^{7}$, Neethu Mary ${ }^{8}$ \\ ${ }^{1}$ Assistant Professor, Department of Community Medicine, Sree Narayana Institute of Medical Sciences. \\ ${ }^{2}$ Assistant Professor, Department of Community Medicine, Sree Narayana Institute of Medical Sciences. \\ ${ }^{3}$ Assistant Professor, Department of Community Medicine, Sree Narayana Institute of Medical Sciences. \\ ${ }^{4}$ Assistant Professor (Biostatistics), Department of Community Medicine, Sree Narayana Institute of Medical Sciences. \\ ${ }^{5}$ Professor, Department of Community Medicine, Sree Narayana Institute of Medical Sciences. \\ ${ }^{6}$ Associate Professor, Department of Community Medicine, Sree Narayana Institute of Medical Sciences. \\ ${ }^{7}$ Assistant Professor, Department of Community Medicine, Sree Narayana Institute of Medical Sciences. \\ ${ }^{8}$ Tutor, Department of Community Medicine, Sree Narayana Institute of Medical Sciences.
}

\begin{abstract}
\section{BACKGROUND}

Breastfeeding is an extremely important and cost-effective intervention for the healthy growth and development of infants and young children. Physicians have an essential role in promoting breastfeeding as the ideal method of infant feeding. Medical students are also expected to have basic knowledge about breastfeeding practices so that they can guide the community to promote breastfeeding.

This study was done to assess the knowledge regarding breastfeeding among medical students and to study the impact of the educational intervention.
\end{abstract}

\section{MATERIALS AND METHODS}

After getting approval from the research and ethical committee of the institution, an educational interventional study was conducted among the first year medical students. After obtaining informed consent, a baseline survey was conducted after their routine class hours using a pretested, semi-structured, self-administered questionnaire to assess the knowledge regarding breastfeeding. This was followed by an educational session regarding correct breastfeeding practices. Post-test survey was conducted after the educational intervention using the same questionnaire to assess the impact of education.

\section{RESULTS}

Out of the total 100 medical students studying in the first semester, 95 students who were present on the day of study participated. The female students constituted 69\%. Their mean age was 19 years. The median score in knowledge improved from 14 to 20 after intervention and this was statistically significant $\mathrm{Z}=8.234, \mathrm{p}<0.001$.

\section{CONCLUSION}

Overall knowledge of the students regarding breastfeeding was low before intervention, and there was a significant increase in knowledge after intervention. It is suggested to include integrated teaching for the first year medical students on the knowledge and importance of breastfeeding along with their anatomy and physiology classes related to this subject. This would improve their knowledge in this aspect, and this knowledge can be imparted to the community.

\section{KEYWORDS}

Exclusive Breastfeeding, Interventional, Medical Students.

HOW TO CITE THIS ARTICLE: Thomas AM, Reshma, Dinesh A, et al. An interventional study on knowledge of breastfeeding among medical students in a medical college of central Kerala. J. Evolution Med. Dent. Sci. 2017;6(19):1508-1511, D0I: $10.14260 /$ Jemds/2017/331

\section{BACKGROUND}

Breastfeeding is a universal phenomenon common to all cultures. In the last 2 decades, there is a universal awareness of advantages of breast milk.

Financial or Other, Competing Interest: None

Submission 27-01-2017, Peer Review 20-02-2017,

Acceptance 27-02-2017, Published 06-03-2017.

Corresponding Author:

Dr. Ann Mary Thomas,

Assistant Professor,

Dept. of Community Medicine,

Sree Narayana Institute of Medical Sciences,

Chalakka,

Ernakulam-683594.

E-mail: marykuncheria@gmail.com

DOI: $10.14260 /$ jemds $/ 2017 / 331$

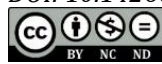

In the western world, there have been increased trends of breastfeeding in recent years. On the other hand, there has been a decline in breastfeeding in the developing countries. Breastfeeding is extremely important for the healthy growth and development of infants and young children; it is the best initial food for babies and it is the fundamental right of every child.(1) The United Nation International Children's Fund/World Health Organization (UNICEF/ WHO 2009) estimates that breastfed children have at least six times greater chance of survival in the early months than children who were not breastfed. The global goal for optimal maternal and child health and nutrition support is that women should exclusively breastfeed their infants for the initial 6 months of life. In addition to the nutritional and psychological values of breast milk, it contains antibodies that help to protect the baby against many common childhood diseases. 
Breast milk is clean, always at the right temperature, inexpensive and nearly every mother has more than enough of this high quality milk for her baby.(2)

Studies have also shown that the duration of breastfeeding was inversely associated with the risk of overweight. Among the children who had never been breastfed, $4.5 \%$ were obese as compared to $2.8 \%$ in breastfed children.(3)

Though we expect health care professionals including doctors, nurses and various other health workers to be well informed regarding breastfeeding issues, studies have shown that it is not completely true. Studies assessing the knowledge of health professionals regarding breastfeeding have shown that they are still unaware about benefits of breastfeeding and we need to adopt more organised measures to promote breastfeeding. There is a worldwide need for improving health professionals' knowledge in lactation physiology and breastfeeding management. Health care professionals play a major role in promoting breastfeeding among mothers in institutional setup. Successful promotion depends upon their knowledge, attitude, motivation and communication skills. (4-5)

It is also seen that there is lack of fulfilling the WHO ten steps initiative for proper breast-feeding among female health care workers in tertiary care hospitals.(6-7)

Since physicians and health workers are in an important position to support and promote breastfeeding as the ideal method of infant feeding, they need accurate, current and scientific information about this.(8-12) A study done on medical students revealed that only Community Medicine and Paediatric courses were the most common sources of information on breastfeeding.(11) The child health indicators are alarming in our country and enable us to understand the importance of investing into nutrition of mothers and children. Multiple child health programmes have been implemented to improve child health and some indicators have shown progress. Breastfeeding is an age old art and science in child rearing which holds its significance even today. It is an unequalled way of providing ideal food for the healthy growth and development of infants; also an integral part of the reproductive process with important implications for the health of mothers.(13) Despite the marked advantages of breastfeeding, its popularity has declined significantly in many parts of the world.

Art and science of breastfeeding depend on the quality of education of the mother. Medical professionals play an important role in providing behaviour change communication to mothers.(14) Community and the family members seek medical advice from health providers like medical students/doctors. Therefore, they should have appropriate knowledge on basic breastfeeding practices. This study was conducted to assess the knowledge of medical students regarding Breastfeeding and to impart knowledge. Medical students being the future physicians will be the first line in dealing with breastfeeding related problems. The medical curriculum should lay emphasis on the importance of breastfeeding in the first year of medical curriculum also and all possible measures should be taken to support and promote breast-feeding.

\section{MATERIALS AND METHODS}

After getting the approval from the Institutional Research and Ethical Committee, an interventional study was done among the $1^{\text {st }}$ year medical students after their routine class hours.
Pretested semi-structured questionnaire containing 25 questions was self-administered after getting their written informed consent. Their initial knowledge on breastfeeding was assessed. Then knowledge was imparted on breastfeeding regarding the initiation, frequency and duration using audio-visual aids. Immediately after the class a post-test was done to re-assess their knowledge using the same questionnaire. For assessment of knowledge, a grading system was used based on the scores obtained. One score was given for each correct answer. The maximum score obtained was 25 and minimum was 0 . The score grading was as follows:

$0-7=1$ (Poor)

$8-13=2$ (Satisfactory)

$14-19=3$ (Good)

20-25=4 (Excellent)

Data was entered in MS Excel and analysed using SPSS 17 software. Statistical methods included Chi-square test and Wilcoxon sign rank test. A p value of $<0.05$ was considered as statistically significant.

\section{RESULTS}

A total of 95 students took part in the study. Among them, 66 (69\%) were female and 29 (31\%) were male.

\begin{tabular}{|c|c|c|c|c|}
\hline $\begin{array}{c}\text { Questions with } \\
\text { Correct Responses }\end{array}$ & $\begin{array}{c}\text { Pre-Test } \\
\text { n (\%) }\end{array}$ & $\begin{array}{c}\text { Post-Test } \\
\text { n (\%) }\end{array}$ & $\mathbf{X}^{2}$ & $\mathbf{p}$ \\
\hline $\begin{array}{c}\text { Exclusive } \\
\text { breastfeeding }\end{array}$ & $\begin{array}{c}78 \\
(82 \%)\end{array}$ & $\begin{array}{c}90 \\
(94.73 \%)\end{array}$ & 7.403 & 0.007 \\
\hline $\begin{array}{c}\text { Immunological } \\
\text { benefits }\end{array}$ & $\begin{array}{c}67 \\
(70.52 \%)\end{array}$ & $\begin{array}{c}86 \\
(90.52 \%)\end{array}$ & 12.116 & $<0.001$ \\
\hline Prevention of obesity & $\begin{array}{c}40 \\
(42.10 \%)\end{array}$ & $\begin{array}{c}90 \\
(94.7 \%)\end{array}$ & 60.897 & $<0.001$ \\
\hline $\begin{array}{c}\text { Frequency of } \\
\text { breastfeeding }\end{array}$ & $\begin{array}{c}26 \\
(27.31 \%)\end{array}$ & $\begin{array}{c}56 \\
(58.94 \%)\end{array}$ & 19.309 & $<0.001$ \\
\hline \multicolumn{4}{|c|}{ Table 1. Distribution of Study Subjects who gave } \\
Correct responses in Pre-test and Post-test
\end{tabular}

Table 1 shows a significant gain in knowledge pertaining to breastfeeding after the intervention.

\begin{tabular}{|c|c|c|c|c|}
\hline Category & Median & IQR & z & p \\
\hline Pre-test & 14 & $11-15$ & \multirow{2}{*}{$8.234^{*}$} & $<0.001$ \\
\hline Post-test & 20 & $19-21$ & & \\
\cline { 1 - 3 } & &
\end{tabular}

Table 2. Comparison of Maximum Scores of Respondent's knowledge on Breastfeeding in Pre-test and Post-test

* Wilcoxon sign rank test. IQR: Interquartile range.

Table 2 shows the median knowledge score on breastfeeding was 14.0 and following educational intervention, the median score increased to 20.0. This was statistically significant $(\mathrm{z}=8.234, \mathrm{p}=<0.001)$.

\begin{tabular}{|c|c|c|c|c|}
\hline \multirow{2}{*}{$\begin{array}{c}\text { Knowledge } \\
\text { Score }\end{array}$} & \multicolumn{2}{|c|}{ Category } & $\left(\mathrm{X}^{2}\right)$ & $\mathbf{p}$ \\
\hline & $\begin{array}{l}\text { Pre-test } \\
\text { n (\%) }\end{array}$ & $\begin{array}{l}\text { Post-test } \\
\text { n (\%) }\end{array}$ & \multirow{5}{*}{$\begin{array}{l}17.56 \\
\mathrm{df}=6\end{array}$} & \multirow{5}{*}{$<0.001$} \\
\hline Poor & $4(4.2 \%)$ & 0 & & \\
\hline Satisfactory & $41(43.2 \%)$ & $3(3.2 \%)$ & & \\
\hline Good & $49(51.6 \%)$ & $37(38.9 \%)$ & & \\
\hline Excellent & $1(1.1 \%)$ & $55(57.9 \%)$ & & \\
\hline \multicolumn{5}{|c|}{$\begin{array}{l}\text { Table 3. Association between Scores } \\
\text { in Baseline and End Line Survey }\end{array}$} \\
\hline
\end{tabular}

Table 3 shows that the respondents with excellent score increased from $1.1 \%$ to $57.9 \%$ following educational 
intervention and this was statistically significant $\left(X^{2}=17.13\right.$, $\mathrm{df}=6, \mathrm{p}<0.001)$.

\section{DISCUSSION}

This study aimed to assess and improve the knowledge of the first year medical students regarding breastfeeding practices. In our study, 78 medical students (82.1\%) knew the concept of exclusive breastfeeding in the pre-test and after the intervention, this improved to $94.73 \%$. In contrast a study among Medical Students of Ziauddin University, Karachi only $42 \%$ knew what is exclusive breastfeeding and 33\% said that weaning should be started between 4-6 months.(15)

In our study, $31 \%$ students had a false notion that water should be given during exclusive breastfeeding. This misconception was also seen in an another study done on college going female students $(20 \%)$ who said Ghutti and honey can be given as prelacteals.(16)

According to the study done on medical students of Ziauddin University, 26\% students felt that colostrum should be discarded.(15) But in our study, the knowledge on importance of colostrum was known to $95.78 \%$ students before intervention and increased to $98.94 \%$ after it.

Sixty seven students (70.52\%) had knowledge on immunological benefits of breast milk in the pre-test and this increased to $86(90.52 \%)$ after the intervention. Bottle feeding is regarded as a risk factor for common childhood illnesses like diarrhoea and upper respiratory infections, which are major causes of infant mortality, $(16,13)$ therefore, the awareness of benefits of breast milk in preventing illness among our medical students is good.

Our study showed that only 40 students $(42.10 \%)$ had knowledge on how breast milk prevents obesity in childhood in the pre-test and 90 (94.7\%) gained knowledge in the posttest.

Among 95 students we studied, 48 (50.52\%) were aware about the transmission of HIV infection through breast milk prior to intervention. 26 more students (77.89\%) gained knowledge in the post-test.

Only $26(27.36 \%)$ had knowledge on how frequently newborns should be breastfed in the pre-test and in the posttest 30 more students (58.94\%) gained knowledge.

\section{CONCLUSION}

The overall initial knowledge of medical students on breastfeeding was low and there was a marked improvement in their knowledge after intervention. So educational intervention is an effective tool to improve the knowledge regarding breastfeeding. Regular sessions should be held in medical colleges from the first year onwards to reinforce the knowledge of the medical students regarding the same as they are the future health care providers

\section{Recommendations}

The present study has clearly shown that the baseline knowledge with respect to many parameters was poor to good, and educational intervention definitely made a surge in their knowledge.

Medical students being the future physicians will be in the forefront for dealing with mothers on breastfeeding related problems.

The medical curriculum should lay emphasis on maternal and child nutrition. Optimal breastfeeding practices must be taught at all levels of medical education. An integrated teaching schedule on the breastfeeding practices should be advocated to the first year medical students along with the anatomy and physiology of mammary gland so that they can impart appropriate knowledge to the community and to their family members on the importance of breastfeeding.

\section{Limitations}

Post-test was done immediately.

We could assess knowledge only on the basis of selected questions.

\section{ACKNOWLEDGEMENTS}

The authors acknowledge the encouragement provided by our Principal Dr. Raju Antony and help provided by our house surgeons, Dr. Afaf Koya, Dr. Angela S M, Dr. Arjun C B, Dr. Aswathi C R, Dr. Boney Priya P Jose, Dr. Deephi Shibu. We also thank the first year medical students who took part in this study.

\section{REFERENCES}

[1] Afzal MF, Saleemi MA, Asghar MF, et al. A study of knowledge, attitude and practice of mothers about breastfeeding in children. Ann King Edward Med Coll 2002;8:28-9.

[2] Vashishtha VM. The state of the world's children 2009: maternal health is the key to achieve MDGs 4 and 5. Indian pediatr 2009;46(3):233-4.

[3] Harder T, Bergmann R, Kallischnigg G, et al. Duration of breastfeeding and risk of overweight: a metaanalysis. Am J Epidemiol 2005;162(5):397-403.

[4] Al-binali AM. Knowledge, attitude and practice of breast-feeding among female health care workers in tertiary care hospitals. Med J Cairo Univ 2012;80(2):159-64.

[5] Lawrence RA, Lawrence RM. Breastfeeding a guide for medical profession. $4^{\text {th }}$ edn. St. Louis, Missouri, Mosby 1994:118-48, 285-306,912-20.

[6] Sultana S. Knowledge regarding breastfeeding practices among nurses in maternity units of health care facilities in Islamabad. Ann Pak Inst Med Sci 2012;8(4):249-51.

[7] Protecting, promoting and supporting breastfeeding: The special role of maternity services, a joint WHO/UNICEF statement published by the World Health Organization available from http:// www.unicef.org/newsline/tenstps.htm [last accessed on 2016 Dec28].

[8] Guise JM, Freed GL. Resident physician's knowledge of breastfeeding and infant growth. Birth 2000;27(1):4953.

[9] Williams EL, Hammer LD. Breastfeeding attitudes and knowledge of pediatricians-in-training. Am J Prev Med 1995;11(1):26-33.

[10] Leavitt G, Martinez S, Ortiz N, et al. Knowledge about breastfeeding among a group of primary care physicians and residents in Puerto Rico. J Community Health 2009;34(1):1-5.

[11] Al-Nassaj HH, Al-Ward NJ, Al-Awqatil NA. Knowledge, attitudes and sources of information on breastfeeding among medical professionals in Baghdad. East Mediterr Health J 2004;10(6):871-8. 
[12] Ahmad SR, Thaher MA, Addepalli C. Knowledge and attitudes of anganwadi workers about breastfeeding in the field practice area of tertiary care hospital. Hyderabad National Journal of Community Medicine 2016;7(5):413-6.

[13] Anjum Q, Ashfaq T, Siddiqui H. Knowledge regarding breastfeeding practices among medical students of Ziauddin University Karachi. JMPA 2007;57(10):480-3.

[14] Bukhari SSI, Najmi K, Shareef S, et al. Perception of college going females regarding breastfeeding: an epidemiological profile. JPMA 2003;53(6):258-301.
[15] Global strategy for infant and young child feeding. The optimal duration of exclusive breastfeeding WHA54/INF.DOC./4 Provisional agenda item 13.1, 2001.

[16] Vidya GS, Renuka M, Kulkarni, et al. Impact of educational intervention on knowledge regarding infant feeding practices among medical students at Mysore. International Journal of Health and Allied Sciences 2015;4(4):230-3. 